\title{
PERAN RESPIRATOR DALAM PENCEGAHAN DAMPAK KESEHATAN AKIBAT POLUSI UDARA (STUDI KASUS DESA KLARI)
}

\author{
Vita Efelina1), Najmudin Fauji2), (qual Maulana ${ }^{3)}$, Eri Widianto4), Sarah Dampang ${ }^{5)}$, \\ Riza Ibnu Adam ${ }^{6}$, Endah Purwanti ${ }^{7}$, Reni Rahmadewi ${ }^{8}$, Billy Nugraha9) \\ ${ }^{1,7)}$ Program Studi S-1 Teknik Lingkungan, Fakultas Teknik, Universitas Singaperbangsa Karawang, Jawa Barat, \\ Indonesia \\ ${ }^{2,4)}$ Program Studi S-1 Teknik Mesin, Fakultas Teknik, Universitas Singaperbangsa Karawang, Jawa Barat, Indonesia \\ ${ }^{3,6)}$ Program Studi S-1 Teknik Informatika, Fakultas IImu Komputer, Universitas Singaperbangsa Karawang, Jawa Barat, \\ Indonesia \\ 5)Program Studi S-1 Teknik Kimia, Fakultas Teknik, Universitas Singaperbangsa Karawang, Jawa Barat, Indonesia \\ 8)Program Studi S-1 Teknik Elektro, Fakultas Teknik, Universitas Singaperbangsa Karawang, Jawa Barat, Indonesia \\ 9)Program Studi S-1 Teknik Industri, Fakultas Teknik, Universitas Singaperbangsa Karawang, Jawa Barat, Indonesia
}

Corresponding author : Vita Efelina

E-mail : vita.efelina@staff.unsika.ac.id

\section{Diterima 30 November 2021, Disetujui 03 Desember 2021}

\begin{abstract}
ABSTRAK
Peran Respirator Dalam Pencegahan Dampak Kesehatan Akibat Polusi Udara Di Desa Klari, Kecamatan Klari, Kabupaten Karawang. Kegiatan ini di latar belakangi Desa Klari yang memerlukan perhatian terhadap peran respirator akibat dampak dari polusi udara. Selain itu, diharapkan dengan adanya Kegiatan Kuliah Kerja Nyata (KKN) ini dapat membantu masyarakat dalam meningkatkan kesadaran masyarakat akan pentingnya dampak polusi udara bagi Kesehatan di Desa Klari Kecamatan Klari. Hal ini dilakukan dengan cara menanyakan serta membagikan kuisioner ke masyarakat Desa Klari dengan adanya peran respirator bagi dampak Kesehatan akibat polusi udara. Dengan tingkat kesadaran masyarakat yang masih minim terhadap pentingnya peran respirator terhadap Kesehatan akibat polusi udara. Hal ini didasari dengan kondisi polusi udara di Desa Klari yang terbilang tidak terlalu baik akibat adanya polusi dari banyaknya kendaraan bermotor, asap pabrik, dan kegiatan pembakaran yang sembarangan. Dengan adanya kegiatan KKN di Desa Klari diharapkan tidak hanya dalam peningkatan peran respirator bagi masyarakat Klari tapi dihimbau bagaimana cara menanggulangi polusi udara dengan cara menanam pohon yang mengandung daya serap gas karbondioksida $\left(\mathrm{CO}_{2}\right)$ dan pembuatan tong sampah guna mengurangi tingkat volume sampah di lingkungan Desa Klari.
\end{abstract}

Kata Kunci: respirator; polusi; karbondioksida $\left(\mathrm{CO}_{2}\right)$; desa klari; volume.

\begin{abstract}
The Role of Respirators in Preventing Health Impacts Due to Air Pollution in Klari Village, Klari District, Karawang Regency. This activity is in the background of Klari Village which requires attention to the role of respirators due to the impact of air pollution. In addition, it is hoped that this Real Work Lecture (KKN) activity can help the community in increasing public awareness of the importance of the impact of air pollution on health in Klari Village, Klari District.This is done by asking and distributing questionnaires to the Klari Village community with the role of respirators for health impacts due to air pollution. With the level of public awareness that is still minimal on the importance of the role of respirators on health due to air pollution. This is based on the condition of air pollution in Klari Village which is not very good due to pollution from many motorized vehicles, factory smoke, and indiscriminate burning activities. With the KKN activities in Klari Village, it is expected not only to increase the role of respirators for the Klari community but are also encouraged to overcome air pollution by planting trees that contain carbon dioxide gas absorption $\left(\mathrm{CO}_{2}\right)$ and making trash cans to reduce the level of waste volume in the Klari Village environment. .
\end{abstract}

Keywords: respirators; pollution; carbon dioxide $\left(\mathrm{CO}_{2}\right)$; klari village; volume

\section{PENDAHULUAN}

Respirator merupakan suatu alat pelindung diri yang dipakai di wajah, setidaknya meliputi hidung dan mulut. Pelindung diri ini berfungsi untuk mengurangi risiko bahaya partikel di udara, gas dan uap. Pemakai respirator haruslah memahami cara pemakaiannya agar respirator dapat berfungsi secara optimal. (Faisal Haruyuki Dewi, 2017).

Setiap pemakai respirator harus menjalani pelatihan tentang bagaimana cara memakai alat tersebut. Selain itu terdapat pula 
suatu upaya memastikan pemakai respirator telah memakai dengan benar. Upaya ini disebut dengan fit testing. Jenis fit testing ada dua yaitu kualitatif dan kuantitatif. Secara singkat prosedur fit testing adalah pemakaian respirator, kemudian diberikan pajanan tertentu dan dilihat apakah ada kebocoran atau tidak. Respirator dapat dibagi berdasarkan cara pemakaian dan mekanisme kerja yakni klasifikasi berdasarkan cara pemakaian. Pembagian jenis respirator dapat diklasifikasikan berdasarkan cara pemakaian yaitu respirator pakai ketat (tight fitting) dan longgar (loose fitting). Respirator pakai ketat adalah respirator yang cara pakainya secara ketat menutupi setengah wajah ataupun seluruh wajah. Tepi respirator berfungsi sebagai pembatas kedap dengan udara luar. Sedangkan respirator pakai longgar berupa helm atau kerudung yang menutupi seluruh kepala. Dan klasifikasi berdasarkan mekanisme kerja maka respirator dibagi menjadi dua yaitu respirator pemurni udara (air purifying) dan pemasok udara (air supplying). Mekanisme respirator pemurni udara bekerja dengan cara menghilangkan kontaminan dari udara, salah satu contoh respirator ini yang banyak dipakai adalah N95.

Desa Klari sangat diperlukannya pengoptimalan penggunaan respirator dalam kegiatan peindustrian agar kesehatan penduduk Desa Klari dapat terjaga dengan baik. Selain itu, di masa pandemi ini sesuai dengan Keputusan Presiden Nomor 11 Tahun 2020 Tentang Penggunaan Masker dan Penyediaan Sarana Cuci Tangan Pakai Sabun (CTPS) Untuk Mencegah Penularan Coronavirus Desease-19 yang mengharuskan masyarakat seluruh Indonesia memakai alat perlindungan pernafasan (respirator). Dalam rangka upaya pengoptimalan untuk kesehatan penduduk di Desa Klari, elemen pemerintahan serta lembaga-lembaga pendidikan di Desa Klari menyediakan beberapa fasilitas guna seperti adanya alat pencuci tangan, pembersih tangan (hand sanitizer), bahkan menyediakan alat perlindungan pernafasan (respirator) berbentuk medis, non medis dan kain.

Pelaksanaan program pengabdian ini di Desa Klari Kecamatan Klari yang berada di Kabupaten Karawang. Hal ini dikarenakan di desa tersebut masih kurangnya edukasi/sosialisasi mengenai menjaga kelestarian lingkungan dari mulai memakai masker, mencuci tangan, dan menerapkan protokol kesehatan. Untuk itu kami selaku mahasiswa dan mahasiswi melakukan kunjungan guna memberi arahan kepada masyarakat desa Klari untuk meminimalisirkan hal-hal yang tidak diinginkan.
Maka pengabdian yang dilakukakan ini bertujuan agar masyarakat desa Klari bisa lebih menerapkan protokol kesehatan guna menghindari polusi yang ada di sekitaran desa Klari dengan cara memakai masker, menanam tanaman/pohon yang dapat membantu berkurangnya sedikit polusi udara dengan harapan bisa membantu masyarakat desa Klari saat ini.

\section{METODE}

Metode penelitian yang dilakukan menggunakan metode studi kasus dengan cara memperoleh data melalui wawancara, observan, survei ataupun pemeriksaan dokumen Penelitian ini menggunakan ruang lingkup yang terbatas sehingga dapat memungkinkan untuk melakukan penelitian secara mendalam khususnya dalam bidang Kesehatan Lingkungan yaitu bidang yang akan diteliti yang terintegrasi dalam Peran Respnator untuk meningkatkan kesadaran guna mencegah dampak kesehatan akibat polusi udara di desa klari

\section{HASIL DAN PEMBAHASAN \\ Kegiatan Sosialisasi respirator di SD Negeri 1 Klari}

Pada bagian sosialisasi tahapan kegiatan yang akan dilakukan pada siswa maupun siswi yang belajar di SD Negeri 1 Klari ini diberikan edukasi tentang Peran Respirator dalam pencegahan dampak Kesehatan akibat polusi udara dan diberikan pemahaman mengenai respirator, peran respirator, polusi udara, dampak polusi udara bagi Kesehatan, pencegahan dalam meminimalisir polusi udara.

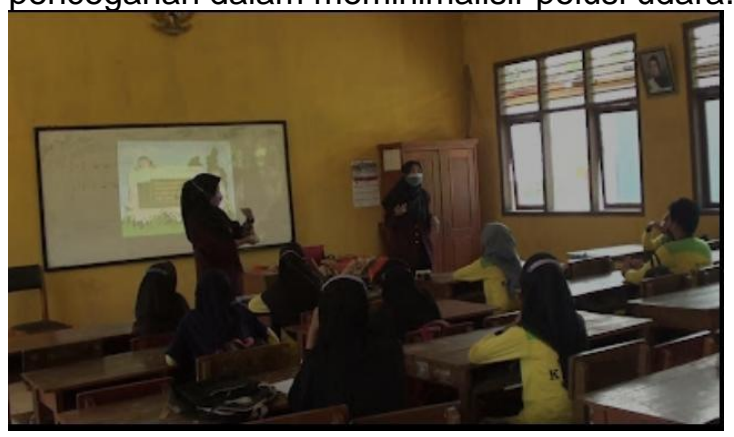

Gambar 1. Sosialisasi respirator di SD Negeri 1 Klari

\section{Kegiatan Penghijauan lahan di SD Negeri 1 Klari}

Pada bagian penghijauan lahan, tahapan kegiatan yang akan dilakukan yaitu mengarahkan, membimbing serta melakukan penanaman tanaman/tumbuhan yang dilakukan oleh siswa maupun siswi SD Negeri 1 Klari untuk menanam 3 jenis tanaman yaitu Sansevieria/Lidah Mertua, Sawo Kecik, dan juga manggis. Nantinya siswa dan siswi 
berkerja sama dalam menanam tanaman tanaman ini seperti menggali tanah, menanam tanaman, memberikan air untuk tanaman, dan juga memberikan pupuk.

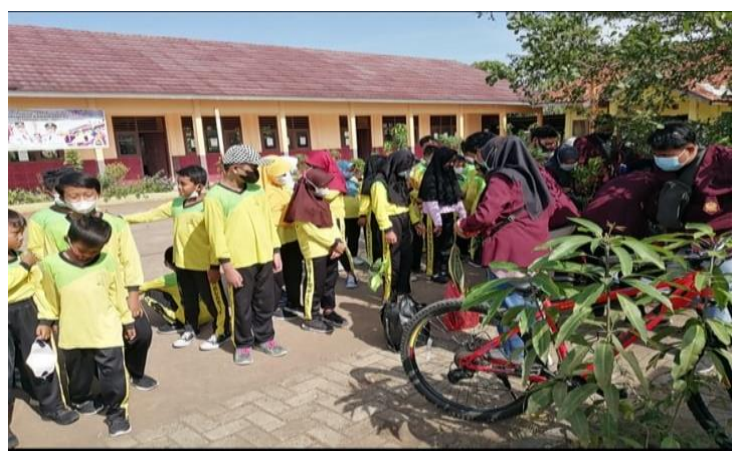

Gambar 2. Kegiatan Penghijauan lahan di SD Negeri 1 Klari

\section{Kegiatan Pembagian masker kepada warga desa Klari}

Kegiatan yang dilakukan pada warga di desa Klari adalah dilakukan pembagian masker kepada masyarakat/warga di desa klari oleh kami, dengan dibagikan nya masker kepada warga maka dampak dari polusi udara akan dapat berkurang dikarenakan warga memakai Alat Pelindung Diri(APD) yaitu respirator/masker yang dapat menghalangi partikel - partikel kecil yang dapat masuk ke dalam tubuh melalui hidung atau mulut seseorang.

Hasil yang dicapai pada Kegiatan dari Kuliah Kerja Nyata (KKN) di Desa Klari Kecamatan Klari adalah sebagai berikut:Warga mendapatkan masker gratis, Desa mendapatkan bantuan masker dan beberapa lokakarya, Siswa / Siswi dapat mengetahui pengetahuan lebih terhadap polusi udara dan hal yang terjadi pada saat ini, Sekolah Dasar Desa Klari mendapatkan beberapa tanaman untuk meningkatkan kadar oksigen di sekitar lingkungan sekolah.

Tindak lanjut dari kegiatan ini adalah menanam pohon, membagikan masker kepada masyarakat sekitar, dan melakukan penyuluhan di SDN KLARI 1. Dengan diadakannya kegiatan menanam pohon di SDN KLARI 1 dapat mengurangi dan mencegah terjadinya polusi udara di SDN KLARI 1. Kegiatan berikutnya yakni membagikan masker kepada masyarakat sekitar untuk mencegah polusi udara masuk ke dalam tubuh masyarakat sekitar, dan kegiatan yang terakhir melakukan penyuluhan di SDN KLARI 1 tentang bagaimana cara menanam pohon yang benar, mengedukasi para siswa mengenai fungsi dari pohon terhadap pencegahan polusi udara, serta memberi sedikit materi mengenai peran dan fungsi tanaman terhadap polusi udara.

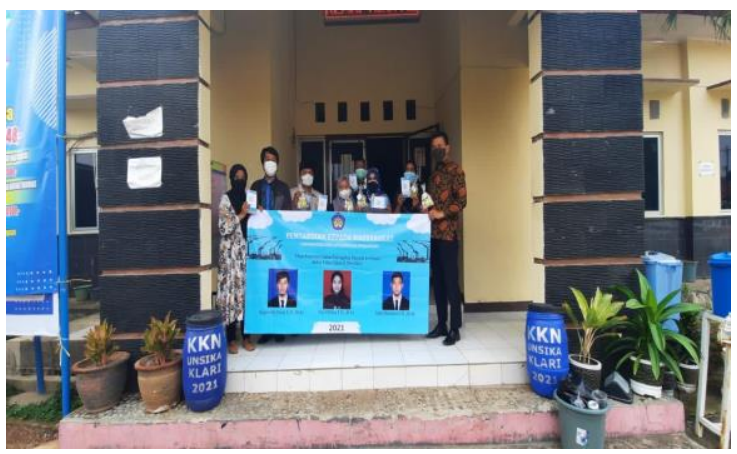

Gambar 3. Pembagian masker kepada warga desa Klari

\section{SIMPULAN DAN SARAN}

Masyarakat perlu menggunakan respirator untuk terhindar dari polusi udara yang ditimbulkan oleh asap pabrik, kendaraan bermotor dan pembakaran sampah secara liar. Agar terhindar dari polusi Respirator dapat membantu sebagai perlidungan pernafasan bagi penggunanya .

\section{UCAPAN TERIMAKASIH}

Ucapan terima kasih tersampaikan kepada Rektor Universitas Singaperbangsa Karawag, Dekan Fakultas Tenik dan Fakultas IImu Komunikasi. Selain itu Masyarakat Desa Klari, Kabupaten Karawang. Hal tersebut telah mendukung dan mempermudah jalannya program pengabdian.

\section{DAFTAR RUJUKAN}

Efelina, V., Dampang, S., Maulana, I., Adam, R. I., Purwanti, E., Rahmadewi, R., \& Nugraha, B. (2021). PENGGUNAAN DRONE UNTUK PENYEMPROTAN DISINFEKTAN DALAM PENCEGAHAN COVID-19 DI MASA PANDEMI (STUDI KASUS DI DESA MARGASARI). SELAPARANG Jurnal Pengabdian Masyarakat Berkemajuan. https://doi.org/10.31764/jpmb.v4i2.4330

Faisal, H. D., \& Susanto, A. D. (2019). Peran Masker/Respirator dalam Pencegahan Dampak Kesehatan Paru Akibat Polusi Udara. Jurnal Respirasi. https://doi.org/10.20473/jr.v3-i.1.2017.1825 